\title{
DA FILOSOFIA PARA OS ESTUDOS ORGANIZACIONAIS: O PERCURSO ONTOLÓGICO DE SCHATZKI NA TEORIA DA PRÁTICA SOCIAL
}

FROM PHILOSOPHY TO ORGANIZATIONAL STUDIES: SCHATZKI'S ONTOLOGICAL PATH IN THE THEORY OF SOCIAL PRACTICE

Recebido em 28.11.2018. Aprovado em 20.02.2019 Avaliado pelo sistema double blind review

Janaína Sousa Loureiro Passos

janaina.s.passos@gmail.com

Programa de Mestrado e Doutorado em Administração/Universidade Positivo - Curitiba/PR, Brasil

ORCID: https://orcid.org/0000-0002-7587-2300

\section{Yara Lúcia Mazziotti Bulgacov}

ybulgacov@gmail.com

Programa de Mestrado e Doutorado em Administração/Universidade Positivo - Curitiba/PR, Brasil

ORCID: http://orcid.org/0000-0003-2661-7810

\section{Resumo}

A multiplicidade de bases ontológicas e caminhos epistemológicos existentes no campo dos estudos organizacionais é crescente. Estudos com bases ontológicas sociais podem ser um caminho para a compreensão do que ocorre nas organizações, que são beneficiadas por perspectivas como, por exemplo, de estudos baseados em práticas. Estes têm como base teorias que buscam o acesso à realidade das organizações por meio das práticas. O presente estudo tem como objetivos explorar a construção da teoria da prática social de Schatzki e compreender sua base ontológica. O artigo se estrutura por meio de uma análise sócio histórica dos textos de Schatzki relativos à construção de sua teoria e amadurecimento de sua ontologia. Como resultado de pesquisa as principais contribuições de Schatzki para os estudos organizacionais são: 1. Rompimento com a tradição positivista; 2 . Rompimento com visões reificantes /classificatórias do indivíduo na medida que toma a prática, conceito holístico, com unidade de analise; 3. Rompimento com teorias abstratas que segmentam a organização, percebendo o nexo de dizeres e fazeres nas organizações e; 4. Maior difusão de métodos de pesquisa, como autoenografia e netnografia. Foram identificadas também três fases ontológicas de Schatzki, proporcionando um entendimento global da construção de sua teoria. Consequentemente, este trabalho ajuda o pesquisador que queira utilizar a teoria da prática social de Schatzki para estudos organizacionais a se apropriar desta lente teórica.

Palavras-chave: Teoria da Prática Social. Theodore Schatzki. Estudos Organizacionais.

\begin{abstract}
The multiplicity of ontological foundations and epistemological paths in the field of organizational studies is growing. Studies with social ontological bases can be a way to understand what happens in organizations that benefit from perspectives such as practice-based studies. These are based on theories that seek access to the reality of organizations through practices. The present study aims to explore the construction of Schatzki's theory of social practice and to understand its ontological basis. The article is structured through a sociohistorical analysis of Schatzki 's texts concerning the construction of his theory and the maturation of his ontology. As a result of research the main contributions of Schatzki to organizational studies are: 1 . The break with the positivist tradition; 2. Breakdown with reifying / classificatory visions of the individual as he takes practice, holistic concept, with unit of analysis; 3 . Break with abstract theories that segment the organization, perceiving the nexus of sayings and actions in organizations; 4. Increased dissemination of research methods, such as autoenography and netnography. Three ontological phases of Schatzki were also identified, providing an overall understanding of the construction of his theory. Consequently, this work helps the researcher who wants to use Schatzki's theory of social practice for organizational studies to appropriate this theoretical lens.
\end{abstract}

Keywords: Social Practice Theory. Theodore Schatzki. Organizational Studies. 


\section{Introdução}

Os estudos organizacionais podem ser conduzidos por múltiplas perspectivas ontológicas e epistemológicas, o que gera uma gama de caminhos de pesquisa neste campo. Neste sentido, Alcadipani (2015) destaca que teorias que têm uma abordagem baseada em práticas têm contribuído recentemente para os estudos organizacionais. Muitos são os pesquisadores que conduzem seus estudos em organizações se utilizando de teorias baseadas em práticas, sendo a expressão "teorias da prática" a cada dia mais utilizada (SCHATZKI, 2012).

Esta expressão teve sua origem na antropologia, onde os estudos de Bourdieu e Giddens podem ser reconhecidos como pioneiros (SCHATZKI, 2012). Posteriormente, de acordo com Schatzki (2012), autores como Reckwitz, Shove, Kemmis e ele próprio começaram a definir e esboçar teorias com base em práticas sociais. Mesmo com uma base filosófica em comum, que tem sua construção atrelada às ideias de Heidegger e Wittgenstein, existe uma multiplicidade de autores e abordagens dentro da perspectiva das práticas.

Dentro dessa perspectiva, alguns autores têm se destacado, como é o caso de Gherardi, Nicolini, Leontiev e Schatzki, dentre outros. Um dos atores que tem contribuído com a perspectiva das práticas, desenvolvendo sua própria teoria, que está em constante desenvolvimento, é Theodore Schatzki.

Schatzki é professor da University of Kentucky, no departamento de Filosofia, área à qual o autor pertence e na qual desenvolve seus estudos. Em uma parte de sua produção acadêmica, surgiu a Teoria da Prática Social, e o autor acabou contribuindo para estudos organizacionais, beneficiando esta área das ciências sociais aplicadas. É intenção do presente artigo explorar a Teoria da Prática Social, desenvolvida por Schatzki (2012), compreendendo a evolução das ontologias social, contextual e plana, que deram base para a construção de sua teoria. O presente artigo também irá evidenciar as contribuições de Schatzki para estudos organizacionais.

Diante do exposto, o principal objetivo deste artigo é fazer uma análise sócio histórica do trabalho de Schatzki, evidenciando a formação e evolução de sua posição ontológica e compreender sua teoria da prática social em estudos organizacionais. Para isso, em um primeiro momento, o artigo traz a exploração da posição ontológica do autor de forma cronológica, evidenciando a formação de sua ontologia em três momentos. Em segundo plano, o artigo mostra a construção de um caminho epistemológico de sua teoria. Subsequentemente, o artigo evidencia as contribuições de ordem ontológica e epistemológica de Theodore Schatzki para os estudos organizacionais, com o objetivo de apresentar um caminho para pesquisadores que queiram utilizar esta teoria como lente de pesquisa.

Para que esta construção fosse possível, foi feita uma pesquisa sobre os artigos e livros publicados pelo autor Theodore Schatzki referentes à Teoria da Prática Social. As publicações do autor foram selecionadas e organizadas em ordem cronológica, para que se pudesse perceber a consolidação de sua ontologia e a formação do caminho epistemológico onde o autor fundamentou suas ideias e consolidou a sua teoria. Foram selecionados os estudos do autor que tiveram relação com a formação de sua ontologia plana e Teoria das Práticas Sociais em estudos organizacionais.

O presente artigo está estruturado em quatro partes principais. A primeira delas é uma visão geral sobre as teorias da prática e a perspectiva do autor Theodore Schatzki. Em seguida é feita uma análise sócio histórica do desenvolvimento da posição ontológica do autor. A terceira parte do artigo traz a definição dos principais conceitos da teoria de Schatzki para serem utilizados em estudos organizacionais que queiram seguir esta teoria como caminho epistemológico. $\mathrm{Na}$ quarta parte, são evidenciadas as contribuições de ordem ontológica e epistemológica que Schatzki trouxe para os estudos organizacionais. Por fim, após a condução deste ensaio teórico, são tecidas as considerações sobre o estudo desenvolvido no presente artigo. 


\section{Teorias da Prática}

Alcadipani (2011) faz uma ressalva sobre as teorias que não são baseadas em práticas, alegando que as pesquisas organizacionais avançam cada vez mais na teorização mas perdem, por um lado, se distanciando cada vez mais do que ocorre de fato nas organizações.

Segundo Bondia (2002), a ciência moderna se distancia da experiência do indivíduo, se pautando em impressões, teorias e experimentos. Para que se possa compreender o que ocorre nas organizações, é necessário que se tenha percepção da experiência do indivíduo dentro da organização. E, por experiência, entende-se "o que ocorre" com o sujeito, o que o toca, o que mexe com ele (BONDIA, 2002). De acordo com esse autor, as experiências são os fatos que ocorrem com as pessoas, que as tocam, coisas que passam pelas pessoas que afetam o mundo delas. Ele diferencia informação de experiência, e separa os dois conceitos. Neste sentido, o autor argumenta que existe muito mais informação do que experiência, e que as pessoas vivenciam poucas experiências, pois ficam no plano das informações. "A experiência é cada vez mais rara por excesso de opinião" (BONDIA, 2002, p. 22).

Esta inquietação sobre uma lacuna entre teoria e prática não é nova em estudos sociais (SANDBERG; TSOUKAS, 2011). E quando se trata de gestão e estudos organizacionais, percebe-se um crescente descontentamento em relação à capacidade das teorias existentes de se aproximarem do que realmente ocorre nas organizações. Segundo Sandberg e Tsoukas (2011), esta lacuna existe por uma diferença entre a racionalidade científica e a racionalidade prática.

Para os autores, a racionalidade científica se pauta numa relação de sujeito-objeto, tendo uma percepção contingencial dos acontecimentos e dados que existem numa organização. Desta forma, a racionalidade científica acaba por deixar os praticantes numa posição obscura da pesquisa, onde não são vistos, sendo assim uma forma de perceber a organização que ignora o que acontece e os atores envolvidos. Esta lógica acaba por buscar dados e relações abstratas, já que não se acessa indivíduos e experiências.

Já a lógica da racionalidade das práticas, apontada por Sandberg e Tsoukas (2011) como derivada principalmente de Heidegger, é uma lógica de entrelaçamento de ações - não meras ações, mas ações significadas, pois vem do conceito de estar no mundo, trazido por Heidegger. Esta lógica desperta a percepção de pesquisadores para elementos como rotinas, ações com entendimento coletivo, indivíduos e suas experiências dentro das organizações, para que se possa entender as práticas organizacionais. Diante disto, esta lógica da racionalidade prática e sua busca no empírico para generalizações que captem o que de fato ocorre nas organizações é uma lógica que dá origem a teorias baseadas em práticas.

As teorias da prática surgem na tentativa de acessar o que ocorre com os indivíduos, suas experiências, e se aprofundar, saindo das ideias abstratas. Elas são um conjunto de teorias que têm como objeto de estudo as práticas sociais. De acordo com Schatzki (1996), as teorias das práticas têm suas raízes teóricas em Bordieu, Guiddens e Wittgenstein. E Schatzki (1996) afirma que o crescimento de estudos com o olhar voltado para as práticas foi constante, até chegar em um momento chamado de practice turn, em que esta perspectiva ganhou corpo. Corpo, mente, cognição, comportamento humano, tudo isso não representa o objeto de estudo, apesar de fazerem parte dele. Este objeto é a prática em si.

A expressão "teorias da prática", de acordo com Schatzki (2012), tem tido seu uso crescente nas últimas décadas. Apesar de existir uma variedade de autores e teorias dentro do que se chama "teorias das práticas", existe um ponto comum central que caracteriza as teorias desta perspectiva.

O principal ponto em comum destas teorias é a sua unidade de análise, que são as práticas. Quando se fala em unidade de análise, pode-se entender a menor unidade que o pesquisador tenta acessar para compreender determinada realidade social. Ou seja, o pesquisador que tem como base teórica uma teoria da prática, irá acessar a organização por meio da observação das práticas, que são as atividades humanas organizadas, carregadas por indivíduos dentro desta organização (SCHATZKI, 2012). É importante 
saber que estas atividades nos estudos organizacionais não são meras rotinas, ou seja, a prática é encarada como um fenômeno social que ocorre, já que as organizações são ambientes sociais (GHERARDI, 2009).

De acordo com Bispo (2013), a practice turn foi influenciada por cinco correntes filosóficas: a tradição marxista, a fenomenologia, o interacionismo simbólico, o legado de Wittgenstein e as mudanças históricas e tecnológicas, que ganham espaço em discussões. Cada uma destas perspectivas filosóficas trouxe à teoria das práticas elementos de análise e discussões que consolidaram esta teoria, como é o caso da linguagem (trazida no legado de Wittgenstein). Assim, a prática foi sendo concebida como fenômeno social.

Vale ressaltar que não existe uma forma padronizada de se referir ao termo "prática”, já que alguns autores utilizam esta palavra no plural e outros no singular. No presente trabalho, o termo "prática" será utilizado no singular, pois assim o autor Schatzki (2012) utiliza. Até porque as teorias das práticas são um conjunto de teorias e autores.

Reckwitz (2012) conseguiu explicar este conjunto quando comparou as teorias das práticas com outras três bases teóricas culturais: o textualismo, o intersubjetivismo e o mentalismo. O autor elenca alguns elementos de estudo e explica o que cada um destes objetos representa para cada uma das quatro teorias que ele confronta. Desta maneira, ele deixa claro o lócus de cada um destes elementos e solidifica a ideia da base das teorias das práticas: sua menor unidade é uma determinada prática (RECKWITZ, 2012). Na descrição do que cada um dos elementos representa para cada uma das teorias, Reckwitz (2012) consegue diferenciar de maneira estrutural as teorias das práticas das outras.

Para fundamentar a comparação entre as quatro teorias, o autor explora a percepção de cada uma delas acerca dos seguintes elementos: corpo, mente, coisas, conhecimento, discurso, estrutura-processos e agente. Com o foco nos símbolos, o textualismo percebe cada elemento como sendo símbolos que formam a cultura. Já o mentalismo tem seu objeto de estudo na mente humana, traçando a dicotomia corpo-mente, buscando compreender cada vez mais esse elemento e a interação com os outros para entender que a cultura é formada ali. O intersubjetivismo, por sua vez, já tem o foco de estudo na interação entre os indivíduos de um grupo, ou seja, a cultura é formada nessas relações. O quarto elemento, a teoria das práticas, tem como objeto de estudo as práticas sociais, ou seja, as ações humanas e valores que determinam estas ações em um dado grupo social. Apesar de sua estrutura de comparação entre teorias ser um elemento que facilita o leitor a compreender parte da essência das teorias das práticas, Reckwitz não explorou elementos fundamentais desta teoria. Ele utilizou elementos que pudessem permitir a comparação entre as quatro teorias e não os elementos que pudessem expressar todo o universo das teorias das práticas.

Quando se trata de teorias da prática, como exposto acima, tem-se perspectivas de diferentes autores como caminho epistemológico para a condução de estudos organizacionais. Uma destas perspectivas, que está em pleno desenvolvimento, é a teoria da prática social de Theodore Schatzki (2012). Esta perspectiva teórica vem sendo trabalhada pelo autor desde 2002, com a publicação de seu texto Practice minded orders, onde ele defende a tese de que as práticas podem explicar a ordem social. Porém, a trajetória de estudos de Schatzki, que o conduz para a teoria da prática social, é iniciada a partir do momento em que seus escritos começam a evidenciar elementos formadores desta teoria.

Conforme mencionado anteriormente, os artigos selecionados para o presente ensaio foram os que estão ligados à formação das bases ontológicas e da formação da teoria de Schatzki. O quadro 1 apresenta a síntese de textos do autor estudados para a construção do presente ensaio, possibilitando visualizar os artigos selecionados em ordem cronológica, com uma ideia geral da contribuição de cada estudo de Schatzki ligado à sua teoria. 


\begin{tabular}{|c|c|c|}
\hline Ano & Título & Ideia Principal \\
\hline 1991 & Spatial Ontology and Explanation & Artigo que apresenta a ontologia espacial. \\
\hline 2000 & $\begin{array}{l}\text { Wittgenstein and the social context of an } \\
\text { individual life }\end{array}$ & $\begin{array}{l}\text { Neste texto, Schatzki introduz a teoria da prática e traz } \\
\text { contribuições de Wittgenstein para sua percepção de } \\
\text { social. }\end{array}$ \\
\hline 2001 & Subject, Body, Place & $\begin{array}{l}\text { Após reflexões sobre o espaço na realidade social, neste } \\
\text { texto Schatzki introduz o elemento corpo como mediador } \\
\text { entre o self e o espaço. A inserção deste elemento é } \\
\text { fundamental para que, posteriormente, ele possa trabalhar } \\
\text { o conceito de incorporar e corporeidade. }\end{array}$ \\
\hline 2002 & Practice minded orders & $\begin{array}{l}\text { Neste artigo, Schatzki sintetiza suas ideias e começa a } \\
\text { esboçar a sua teoria, defendendo a tese de que a ordem } \\
\text { social é definida pelas práticas. }\end{array}$ \\
\hline 2003 & A New Societist Social Ontology & $\begin{array}{l}\text { Uma nova ontologia é apresentada pelo autor neste } \\
\text { momento. A ontologia contextual. }\end{array}$ \\
\hline 2005 & The Sites of Organizations & $\begin{array}{l}\text { Neste texto, Schatzki reafirma sua ontologia contextual } \\
\text { apresentando-a como base para a percepção da realidade } \\
\text { organizacional. Ele sugere que estudos organizacionais } \\
\text { podem se beneficiar desta ontologia e devem partir do } \\
\text { pressuposto de que as organizações são um conjunto de } \\
\text { práticas humanas e arranjos materiais. }\end{array}$ \\
\hline 2006 & On Organizations as they Happen & $\begin{array}{l}\text { Este artigo trata de examinar o que as organizações são e } \\
\text { como elas acontecem. De acordo com Schatzki, a estrutura } \\
\text { de práticas e arranjos materiais definem a organização e } \\
\text { constituem a sua memória. Neste artigo ele defende a ideia } \\
\text { de que a memória organizacional é carregada pela } \\
\text { perpetuação das práticas e sua estrutura. }\end{array}$ \\
\hline 2006 & The time of activity & $\begin{array}{l}\text { Neste texto, Schatzki reconhece o elemento temporal na } \\
\text { atividade, nas práticas. Ele traz a ideia de Heidegger de que } \\
\text { existe uma questão temporal onde as atividades têm } \\
\text { começo, meio e fim, sendo uma questão teleológica. Uma } \\
\text { importante reflexão que o autor faz é que esta dimensão } \\
\text { temporal para as práticas não significa que seja uma } \\
\text { dimensão linear, mas as ações seguem uma lógica temporal } \\
\text { não contínua. }\end{array}$ \\
\hline 2011 & Where the Action Is & $\begin{array}{l}\text { Neste ensaio, a ideia de que a teoria da prática social serve } \\
\text { para estudar fenômenos sociais tanto numa esfera de } \\
\text { macro fenômenos, como numa esfera de } \\
\text { microfenômenos. Ele localiza a ação como ponto de } \\
\text { partida para a compreensão das práticas e conceitua } \\
\text { constelações e pacotes. Neste ensaio também é } \\
\text { apresentada a ideia inicial da flat ontology. }\end{array}$ \\
\hline 2012 & A Primer on Practices & $\begin{array}{l}\text { Este artigo é onde Schatzki faz um apanhado sobre o que } \\
\text { vem se estudando em teorias da prática, define seus } \\
\text { conceitos e sua teoria. É um artigo seminal para quem } \\
\text { estuda este autor. }\end{array}$ \\
\hline 2016 & Practice theory as flat ontology & $\begin{array}{l}\text { Este texto é onde Schatzki apresenta a teoria da prática } \\
\text { como ontologia plana. Ele traz a ideia de que estudos com } \\
\text { esta posição ontológica percebem a realidade social como } \\
\text { um plano com um só nível ou nenhum. }\end{array}$ \\
\hline
\end{tabular}

QUADRO 1: Textos de Schatzki ligados à teoria da prática social e estudos organizacionais, em ordem cronológica (elaborado pelas autoras).

Por ser uma teoria relativamente nova e em constante construção, já que o autor ainda escreve artigos sobre o tema, e por se tratar de um caminho para a pesquisa organizacional, a teoria da prática social de Schatzki (2012) deve ser compreendida a partir de sua origem e embasamento. Esta compreensão se faz necessária para qualquer estudo que tenha como base sua teoria para a apreensão de práticas organizacionais. Vale ressaltar que Schatzki apresenta de forma sólida e estruturada uma teoria própria 
para o estudo de práticas sociais, porém não dá um nome a ela. Então, para que se possa se referir a esta teoria que será explorada no presente trabalho, será utilizado o nome de Teoria da Prática Social. Para que se possa compreender os elementos da Teoria da Prática Social, faz-se necessária uma compreensão da base ontológica que sustenta esta teoria.

\section{O nascimento de uma ontologia das práticas}

A formação de uma ontologia que dá sustentação à teoria da prática social desenvolvida por Schatzki segue um caminho evolutivo, que deixa evidente três fases do autor. A primeira é a da ontologia espacial, que teve seu início em 1991. A segunda fase é a da ontologia contextual, em 2003. E a terceira fase, a atual, é a da ontologia plana, que teve seu início em 2016.

Em 1991, Schatzki escreveu um artigo que trata da ontologia espacial. Este artigo mostra o início da preocupação dele com o espaço como parte relevante nos estudos sociais. De acordo com o autor, as características espaciais de um determinado grupo não diferem de outros aspectos da vida social, ou seja, deveriam ser observados com a mesma importância de outros aspectos. A realidade social deve englobar, além da inter-relação da vida humana, o espaço social.

$\mathrm{Na}$ construção de sua percepção do espaço, Schatzki mostra uma forte influência de Heidegger no que se refere à preocupação da inserção do espaço nos estudos sociais. Trazer o espaço para a análise social, a fim de que esta análise dê conta de todos os aspectos relevantes, é uma percepção que define aspectos de sua ontologia e que traz consequências epistemológicas para os estudos sociais. Este argumento é trazido por Schatzki como contribuição de Heidegger para seus estudos. Porém, o reconhecimento do espaço neste campo não deve ser levado de maneira reducionista, como argumenta o autor.

Mas o fato de se reconhecer o espaço como parte relevante nos estudos sociais não reduz estes estudos ao escrutínio de acontecimentos particulares locais, porque o segundo componente essencial da investigação social é a construção de uma visão ampla que seja "pesquisável" destes acontecimentos (SCHATZKI, 1991, p. 655).

Este argumento mostra que a inserção do espaço como dimensão de análise serve para ampliar a visão do pesquisador acerta da realidade social, ou seja, ela engrandece o estudo e não pode ser reduzida a uma análise superficial do espaço físico das atividades humanas. Então, a percepção deste espaço não é meramente física, como explica Schatzki (1991), o espaço não é um lugar somente, mas o sentido organizado de espaços e caminhos onde as atividades humanas ocorrem.

Pode-se pensar no exemplo de um contexto social de determinado fenômeno, tal como uma guerra. Ela ocorre por meio da inter-relação de pessoas, ações e elementos que constituem a configuração de um contexto, formado por espaços e elementos inter-relacionados. Estes espaços surgem inerentemente à atividade humana, ou seja, vão sendo abertos e transformados à medida em que estas atividades ocorrem, sendo espaços e lugares dentro de um contexto social.

A palavra "contexto" é central para a explicação de Schatzki sobre o elemento espacial, tão explorado pelo autor. Este contexto referido pelo autor é carregado de uma relação de causalidade, onde ações e comportamentos ocorrem moldando o ambiente e sendo moldados por ele. Ele se refere a esta expressão como uma das duas contribuições mais importantes de Wittgenstein para a construção de sua ontologia (SCHATZKI, 2000).

A primeira contribuição trazida para seus estudos é a tese defendida por Wittgenstein de que as pessoas são constitucionalmente seres sociais. A segunda é a ideia de que o contexto social de uma vida individual é um nexo de práticas. No desdobramento destas duas contribuições, Schatzki (2000) reconhece a obrigatoriedade do contexto social para o estudo das práticas e ações. Afinal, como ressalta o autor, a "mente e a atividade humanas são inerentemente amarradas ao contexto social" (SCHATZKI, 2000, P. 101). 
Neste sentido, Schatzki (2001) reconhece três elementos que existem na espacialidade humana: o sujeito, o corpo e o lugar. Ele começa a fazer estudos e reflexões sobre estes elementos a partir da percepção de que o self e o lugar estão inter-relacionados, enquanto se constituem mutuamente. $\mathrm{O}$ sujeito constitui o lugar e, ao mesmo tempo, é constituído por ele. Essa relação cíclica abre espaço para que Schatzki (2001) perceba que nesta relação entre sujeito e espaço algo deve existir para mediá-la. E o mediador desta relação é o corpo. O corpo incorpora ações e carrega um nexo de conhecimentos compartilhados (SCHATZKI, 2001).

As práticas seguem este movimento de constituição mútua entre sujeito e lugar, mediado pelo corpo. As práticas são carregadas pelo corpo. Schatzki (2011) percebe esta relação entre sujeito, corpo e lugar, sem separar corpo e mente, pois ela é parte do sujeito.

Então, quando o foco de Schatzki chega na compreensão da ordem social, ele tem duas ideias formadas. A primeira é a de que a ordem social é estabelecida no movimento das práticas sociais. E a segunda é a ideia de que a mente é parte central deste processo (SCHATZKI, 2002). Neste momento, o autor reconhece a mente como elemento em destaque. A ideia de que a prática forma o contexto central da ordem social é amadurecida, já que esta carrega uma inteligibilidade que governa as atividades humanas. Esta inteligibilidade é processada na mente humana, sendo a mente o elemento central no estabelecimento das práticas. Então, o autor defende a ideia de que a ordem social é estabelecida na mente humana por meio das práticas. Desta forma, a mente é mediadora da ordem social (SCHATZKI, 2002).

Neste sentido, o espaço é enfatizado pois todo o movimento dos elementos que formam as práticas ocorre em um local. E ao descrever a ordem social, Schatzki especifica que elementos são estes. Por ordem social, na visão desse autor, entende-se que se trata de "um arranjo de pessoas e artefatos, pelas quais estes elementos coexistem, no qual estas entidades se relacionam e possuem identidade e significado" (SCHATZKI, 2002, p. 61).

A partir da evolução destas ideias, que sempre enfatizam a espacialidade das práticas, Schatzki (2003) consolida uma segunda fase do seu trabalho. Nasce a ontologia contextual, ou site ontology (SCHATZKI, 2003), que é uma ontologia social.

De acordo com o autor, as ontologias sociais se preocupam em perceber a natureza do social, buscando entender em que consiste o social e qual a estrutura básica da vida social (SCHATZKI, 2003). Quando se fala em ontologias sociais, depara-se com dois campos distintos: as ontologias individualistas e as não individualistas. São perspectivas que diferem entre si por sua maneira de perceber a forma como o meio social é constituído.

De um lado, o campo das ontologias individualistas tem como essência o pressuposto de que os fatos sociais são apenas um produto de constituições de indivíduos e suas relações. De outro, as ontologias não individualistas acreditam que os fatos sociais são reflexo de algo que vai além do indivíduo, além das pessoas, como uma estrutura independente (SCHATZKI, 2003). Quando o autor utiliza a expressão "fatos sociais" é uma forma de diferenciar estes fatos de ações individuais e isoladas, ou seja, os fatos sociais são carregados de uma inteligibilidade coletiva.

Com elementos destas duas perspectivas, surge a site ontology, ou ontologia contextual (tradução livre), que é a ontologia que defende que a vida social é inerentemente atada a um tipo de contexto onde ela (a vida social) acontece (SCHATZKI, 2003). A site ontology defende a ideia de que a natureza do social envolve a identificação do tipo de local onde a vida social existe e se desenvolve. Mas este local é um tipo de contexto. E somente analisando este contexto é que se pode compreender determinada realidade social.

A palavra site vem de sítio, cidade, ou seja, ela expressa a ideia de um local, uma delimitação geográfica de determinado lugar. Mas o site espacial é apenas um tipo de contexto. Não um contexto de estruturas abstratas, mas um tipo específico e bem definido de contexto. 
Estes contextos englobam dimensões da vida social que não devem ser analisadas individualmente. $\mathrm{O}$ entendimento coletivo das ações humanas, tratado como inteligibilidade, é parte deste contexto. A inteligibilidade não é tida como uma particularidade de cada indivíduo, mas como algo coletivo, que cada indivíduo apenas carrega em si. É algo carregado com as práticas. Este entendimento é social, já que várias pessoas compartilham e ele é acessível a qualquer pessoa, estando em um contexto público. Então os fatos sociais são maneiras de pensar, sentimentos e ações que carregam duas características que mostram que eles não são fatos exclusivos de cada indivíduo. Primeiramente, estas maneiras de pensar, sentimentos e ações são externalizados, podem ser percebidos por meio da observação. Segundo, estes elementos exercem um poder coercitivo sobre os indivíduos. Os praticantes são conduzidos a agir, pensar e sentir de determinada maneira, sendo esta inteligibilidade externa a eles, ou seja, coletiva.

Desta maneira, o que a ontologia contextual enfatiza é que os indivíduos que carregam e dão continuidade às práticas estão imersos em campos de significados que as práticas sustentam. Estes campos são contextos específicos de cada prática, como por exemplo, a prática da educação, casamento, economia, política etc.

Em resumo, esta ontologia que marca a segunda fase de Schatzki é a percepção da natureza da existência social como sendo um emaranhado de práticas e arranjos. Para a ontologia contextual, a realidade social é este emaranhado de práticas. E a definição de práticas dentro deste posicionamento ontológico é "atividade humana organizada" (SCHATZKI, 2003, p 191). A prática, para Schatzki (2003), é organizada por um arranjo de inteligibilidades, regras, fins, projetos e valores dados às coisas dentro de um contexto. Cada prática é um conjunto de ações interligadas por entendimentos e regras, numa estrutura teleoafetiva. Por estrutura teleo-afetiva, Schatzki entende que são estruturas normativas, onde determinadas ações são aceitáveis para se chegar a um fim comum (SCHATZKI, 2003).

Percebe-se que a ontologia descrita por Schatzki em sua primeira fase nasceu com a ontologia espacial, conforme explicado anteriormente, na qual o autor reconhece uma espécie de local onde os elementos sociais coexistem e se relacionam. A evolução de seus estudos continua para sua segunda fase evidenciando a ontologia contextual, que percebe este "espaço" como um contexto, um ambiente onde indivíduos, regras, práticas, artefatos estão inseridos.

Seguindo uma linha evolutiva, o último passo de Schatzki em relação a uma ontologia das práticas é a caracterização desta como flat ontology, a ontologia plana (tradução livre), que dá início à sua terceira fase. Nesta fase, Schatzki (2016) caracteriza esta ontologia como plana, por sugerir que a natureza do social existe em apenas um (ou nenhum) plano, não existindo uma diferença de níveis (SCHATZKI, 2016).

Apesar do campo das teorias das práticas comportar uma gama de autores e teorias que são diferentes entre si, para Schatzki (2016), todas as teorias e autores concordam em três pontos. O primeiro ponto de convergência entre os autores é que o termo "práticas" é central para suas teorias. O segundo ponto é que as práticas têm o caráter social, sendo carregadas por vários indivíduos. O terceiro ponto é a percepção de que fenômenos sociais estão enraizados em práticas. E, como Schatzki (2016) ressalta, o segundo e o terceiro ponto de concordância entre os teóricos das práticas têm a ver com a ontologia. Ou seja, as teorias estão partindo de uma só ontologia, que é a ontologia plana.

Esta posição ontológica plana, que parte do pressuposto de que a realidade social é formada por um conjunto de práticas que se relacionam em um nível só, dá suporte à tese de Schatzki (2012) de que uma prática social explica a realidade social na qual ela está inserida. "A ideia que práticas e arranjos formam pacotes implica que práticas e arranjos estão inter-relacionados" (SCHATZKI, 2016, p. 51). Desta maneira, o autor deixa claro que as práticas se relacionam entre si com outras práticas e com conjuntos de práticas.

Pode-se pensar em um exemplo desta posição ontológica na percepção da realidade social de uma organização. Um determinado ritual dentro de um escritório é uma prática, que compõe várias práticas e 
forma arranjos. Por exemplo, uma empresa é um arranjo de práticas (SCHATZKI, 2016). Então, as práticas e arranjos se relacionam dentro de uma malha ou conjunto, em constante movimento de mudança através do tempo (SCHATZKI, 2016).

A exploração de seus relatos sobre as ontologias espacial, contextual e plana deixa evidente a evolução de sua base ontológica. A percepção desta evolução é necessária para a compreensão da teoria das práticas sociais e sua aplicação em estudos organizacionais.

O pesquisador que tem como base a ontologia plana, ao pesquisar as organizações, tem como princípio percebê-las como ambiente social formado por um emaranhado de práticas. A compreensão desta ontologia é o primeiro passo para os estudiosos de organizações que queiram se utilizar da teoria da prática social desenvolvida por Schatzki (2012).

Como forma de visualizar as três fases ontológicas de Schatzki, pode-se observar seus três textos de base, com ano e título na figura 1. Vale ressaltar que as três fases não rompem uma com a outra, mas mostram um refinamento da percepção do autor sobre a natureza da realidade social.

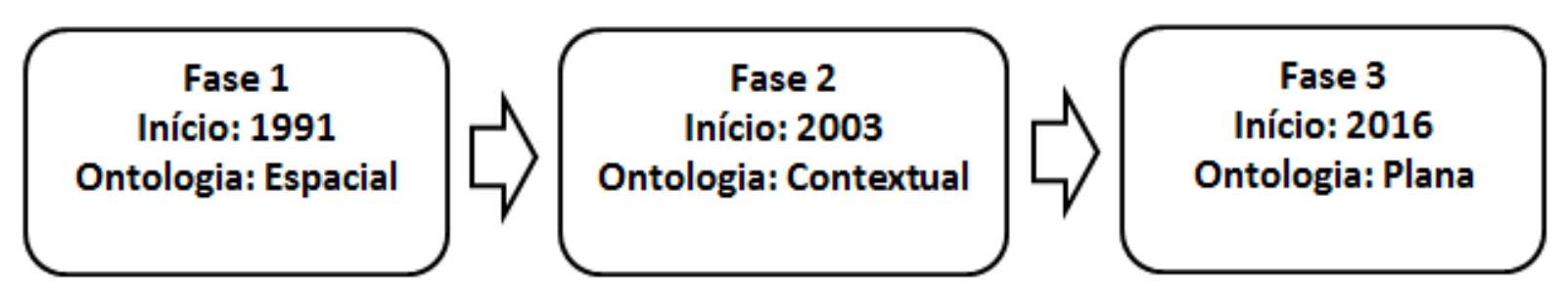

FIGURA 1: Fases de Schatzki com base em textos que apresentam posições ontológicas (Elaborada pelas autoras).

O próximo passo do presente estudo é observar os elementos da teoria da prática social de Schatzki (2012), percebendo-a como base para estudos organizacionais.

\section{A teoria de Schatzki em estudos organizacionais}

Ao consolidar sua ontologia, Schatzki (2003) personifica dois conceitos centrais para os seus estudos. O primeiro deles é o conceito de contexto social que, de acordo com ele, é um emaranhado de práticas que compõe conjuntos maiores de práticas. O segundo conceito é o de prática social, que é, de maneira resumida, uma atividade organizada - atividade esta que é carregada de significado. Estes dois conceitos formam uma base para a teoria da prática social. Eles delineiam caminhos epistemológicos para que a teoria das práticas crie corpo e possa servir de lente teórica para estudos empíricos.

Neste sentido, Schatzki defende a tese de que as práticas sociais explicam a realidade da ordem social na qual estão inseridas (SCHATZKI, 2002). Desta maneira, o autor mostra a relação entre os conceitos de meio social e práticas, explicitando sua ideia de que há uma relação de explicação onde as práticas se formam e são formadoras do meio social.

O autor defende, ainda, a ideia de que as práticas são consolidadas na mente do indivíduo, sendo organizações mentais. E, neste sentido, explica que a mente organiza dizeres e fazeres como práticas. Em outras palavras, Schatzki (2002) explica que "uma prática é um conjunto de dizeres e fazeres, que são organizados por um conjunto de entendimentos, um coletivo de regras e algo que eu chamo de estrutura teleo-afetiva" (SCHATZKI, 2002, p. 58).

A partir desta definição, o autor consolida elementos centrais para sua teoria. Em primeiro lugar, o entendimento é o que dá sentido às regras e liga as ações que compõem uma determinada prática. Ele forma uma consciência coletiva que determina o que dá sentido ao que as pessoas fazem (SCHATZKI 2002). O entendimento coletivo forma o que o autor chama de inteligibilidade. E a inteligibilidade não é 
determinada pelo entendimento de cada indivíduo, mas pelos outros elementos que o autor cita em seu conceito: as regras e a estrutura teleo-afetiva. Ou seja, o conceito de inteligibilidade deriva de sua posição ontológica, já que o autor enfatiza que é no social que os entendimentos são formados, e não no individual.

Desta maneira, Schatzki (2002) defende a ideia de que as regras e a estrutura teleo-afetiva determinam a inteligibilidade das práticas sociais que os indivíduos compartilham. Em outras palavras, pode-se perceber este tipo de estrutura como sendo guiada por um fim onde todos os indivíduos que estão inseridos nela percebem para onde suas ações estão sendo direcionadas e fazem ações condizentes com esta orientação.

Entender estes conceitos e as relações entre eles é o caminho para que se possa compreender a teoria das práticas sociais, pois é a partir destes elementos que Schatzki apresenta esta teoria. Perceber como estes elementos surgem, antes de mais nada, da ontologia do contexto (SCHATZKI, 2000) é outro ponto que irá nortear o pesquisador e familiarizá-lo com a teoria da prática social.

Além destes elementos (inteligibilidade e estrutura teleo-afetiva), as práticas carregam a questão da temporalidade, que é destacada por Schatzki (2012) como sendo sempre presente nas práticas sociais. As práticas, que são um conjunto de atividades organizadas, são eventos temporais e espaciais (SCHATZKI, 2012). Este pressuposto traz para o entendimento da teoria das práticas sociais o elemento temporalespacial como sendo um dos pontos centrais da teoria.

Desta forma, os elementos da teoria das práticas se personalizam, vindo da ontologia contextual para estudos das práticas em determinados contextos, como é o caso das organizações. E fazer pesquisa em organizações, compreendê-las como sistemas sociais, requer que o pesquisador fuja do reducionismo positivista e perceba as organizações e indivíduos pela experiência (BULGACOV, 2012). Para Bulgacov, para se conhecer a realidade organizacional, deve-se adotar uma postura anti positivista que observe o sujeito com base em suas experiências e não o rotule de maneira reducionista, se afastando do que ele realmente é.

Considerando as organizações como tipos de formação social, compreendê-las significa percebê-las como um conjunto de arranjos de práticas que se relacionam entre si (SCHATZKI, 2005). Cada departamento, equipe, com as pessoas e arranjos materiais envolvidos, é um emaranhado de práticas que se relacionam entre si, fazendo com que a organização funcione de determinada forma. Como cada departamento funciona, como as decisões são tomadas, que tipo de política é compartilhada dentro da organização são questões que podem ser compreendidas por meio da análise das práticas sociais que existem dentro delas. Ou seja, cada departamento possui práticas que pertencem a um arranjo. E para acessar este conhecimento, apreendendo as práticas sociais dentro da organização, é necessário acessar as experiências dos indivíduos.

A primeira implicação da perspectiva de Schatzki para os estudos organizacionais é perceber as organizações com base na ontologia plana. Para isso, de acordo com Schatzki (2005), pressupõe-se, em primeiro lugar, que as organizações são um emaranhado de arranjos de práticas, sendo um produto de ações executadas dentro de uma prática. Em segundo lugar, a organização é uma malha, que abrange práticas em graus variados e arranjos materiais novos e antigos. E, em terceiro lugar, as organizações continuam sua existência por meio da perpetuação de suas práticas e manutenção de seus arranjos.

Então, para se estudar organizações, a preocupação central é identificar quais ações a compõem e, em segundo plano, identificar em quais arranjos de práticas estas ações se enquadram (SCHATZKI, 2016). Ou seja, para se estudar organizações com base na Teoria da Prática Social, uma vez que já se compreendeu sua base ontológica, é necessário ter em mente as implicações metodológicas que esta lente teórica traz. 


\section{Implicações metodológicas}

Para a condução de estudos empíricos que se utilizem da teoria da prática social de Schatzki, é necessário, primeiramente, que se tenha o entendimento de sua ontologia, ou seja, perceber a natureza da organização de acordo com a ontologia plana. Como falado anteriormente, o pesquisador que se utiliza desta teoria deve conceber a organização como um emaranhado de arranjos de práticas; então, para operacionalizar sua pesquisa, deve buscar no seu objeto de estudo os elementos que o compõem.

Para isso, o pesquisador deve identificar a malha de arranjos de práticas, buscando entender como cada uma se relaciona com outra dentro da organização (SHCATZKI, 2005). E, para compreender estas relações, é necessário perceber o movimento das práticas, suas estruturas teleo-afetivas, as crenças e valores dos praticantes e como estas práticas se relacionam entre si (de maneira harmoniosa ou não). Por exemplo, como departamentos de uma organização se relacionam, por meio de suas práticas.

Schreiber (2014) conduziu um estudo onde observou a prática de trabalhos escritos em uma faculdade utilizando como base teórica a Teoria da Prática Social de Schatzki (2012). Para fundamentar seu estudo, o conceito de prática de trabalho escrito foi percebido como parte de um arranjo de práticas que "molda e mantém as práticas dentro de um contexto social" (SCHREIBER, 2014, p. 348). Ou seja, a percepção dos elementos da pesquisa é alinhada com o posicionamento ontológico de Schatzki, para que se possa seguir um caminho epistemológico e metodológico compatível com a sua teoria. Por exemplo, a maneira como o pesquisador que se utiliza desta teoria percebe a mente, a capacidade de agência do indivíduo, o próprio indivíduo em si como carregador das práticas. Todas estas percepções são expressadas por Schatzki em seus estudos, servindo como base inicial para se conduzir trabalhos que tenham sua teoria como base de pesquisa.

A metodologia que Schreiber (2014) utilizou foi qualitativa, tendo como estratégia de pesquisa entrevistas semiestruturadas com 27 estudantes. A análise dos dados foi feita de forma que os elementos emergentes da teoria da prática social de Schatzki pudessem ser identificados.

A lente teórica de Schtazki, a qual ele construiu em cima de sua base ontológica - a ontologia contextual e, posteriormente, a plana -, foi o alicerce para a condução do estudo de O'Keeffe et al (2015). Os autores conduziram um estudo sobre a prática de avaliação do design de um Serviço Nacional de Saúde, pois esta prática social é de suma importância para o andamento dos serviços prestados por esta organização.

Os autores acima citados apontam a existência de uma estrutura teleo-afetiva, um conjunto de regras e entendimentos gerais, inteligibilidade e compreensões práticas coletivas, o que faz com que seja aplicável a teoria das práticas sociais para a compreensão da avaliação de design (O'KEEFFE et al, 2015). A aplicação da lente teórica de Schatzki (2012) foi utilizada no estudo prático dos autores, que conseguiram identificar o contexto, os artefatos humanos e não-humanos e perceber a dinâmica da prática estudada. O estudo traz também como contribuição o método de pesquisa da observação participante, com filmagem e gravação de áudio para estudos que utilizem estas bases teóricas, a fim de identificar os nexos de dizeres e fazeres, que são a prática em si.

Percebe-se que, apesar de poucos estudos empíricos que utilizam a Teoria da Prática Social de Schatzki (2012), eles são representações de que a operacionalização desta teoria é possível. Isso posto, ficam evidentes as contribuições de Theodore Schatzki para os estudos organizacionais de ordem ontológica e epistemológica. 


\section{Contribuições de ordem ontológica e epistemológica de Theodore Schatzki para os estudos organizacionais}

Conforme apontam Bulgacov e Vizeu (2011), os estudos organizacionais nasceram de uma base positivista, o que justifica o maior número de estudos nesta área estar partindo do paradigma positivista de pesquisa como base ontológica e, consequentemente, epistemológica.

Romper com a tradição positivista é a primeira contribuição evidente de Theodore Schatzki para os estudos organizacionais. Isto porque, como se pôde observar ao longo da construção de sua ontologia, percebe-se que ela tem a base interpretativista, considerando a realidade das organizações como sendo construída socialmente por meio das práticas.

Apesar de não ser exclusividade do autor, este rompimento deve ser considerado como uma contribuição. Isso porque perceber a realidade social como um plano, que é a essência de sua ontologia, rompe com separações e dicotomias que limitam a compreensão dos fenômenos organizacionais e dos indivíduos nas organizações. Estas separações entre indivíduo, organização, decisões pressupõe uma racionalidade descolada das experiências e emoções, fechando os olhos para a compreensão do que ocorre de fato nas organizações.

Para embasar esta ideia, pode-se perceber essas dicotomias em estudos que tentam classificar o perfil gerencial, ou perfil empreendedor dos indivíduos, na tentativa de classificá-los e categorizá-los. Um estudo que tenha como base ontológica e epistemológica a teoria de Theodore Schatzki busca compreender o fenômeno como uma prática, apreendendo como ele ocorre, e não categorizando arbitrariamente indivíduos carregadores de tais práticas. Posto isso, pode se apontar como contribuição o rompimento com visões reificantes do indivíduo na medida que toma a prática, conceito holístico, com unidade de análise.

Corroborando com esta ideia, Bondia (2002) aponta como lacuna de pesquisa estudos que acessem as experiência e emoções dos indivíduos para se compreender como os fenômenos ocorrem de fato. Neste sentido, pode-se perceber como a ontologia e a epistemologia de Schatzki podem contribuir para estudos que visem preencher esta lacuna.

Desta forma, Schatzki aproxima o pesquisador da compreensão sobre o que realmente ocorre nas organizações, pois, como destaca Alcadipani (2015), os estudos organizacionais têm se distanciado cada vez mais disso, utilizando-se de teorias abstratas que não dão conta dos fenômenos organizacionais. Então, o rompimento com teorias abstratas é uma contribuição trazida por Schatzki para os estudos organizacionais, proporcionada pela percepção do nexo de dizeres e fazeres nas organizações. Olhar os fenômenos organizacionais como práticas alarga a percepção do pesquisador e traz novas descobertas e questões de pesquisa relevantes para o campo dos estudos organizacionais.

Estas contribuições tomam proporções ainda maiores quando se pensa no plano epistemológico, onde caminhos de pesquisa são traçados para apreender a realidade do fenômeno estudado por meio de elementos trazidos por Schatzki. Quando se parte do pressuposto de que as organizações são um emaranhado de práticas interconectadas num plano, regidas por uma estrutura teleo-afetiva, estudar os fenômenos organizacionais requer métodos e estratégias de pesquisa que consigam dar conta destes fenômenos. Pode-se, então, perceber outra contribuição de Schatzki para os estudos organizacionais: uma maior difusão de métodos de pesquisa. Métodos como etnografia e suas nuances, autoetnografia, netnografia, bem como outros que são amplamente utilizados em áreas sociais, como a Antropologia, Sociologia e Psicologia dão sua contribuição para os estudos organizacionais.

Isso posto, no que diz respeito às contribuições trazidas por Schatzki, sua base ontológica e caminho epistemológico trouxeram como maior contribuição aos estudos organizacionais o amadurecimento da Teoria da Prática Social. Esta é uma lente teórica que abre inúmeras possibilidades de pesquisa no campo. 


\section{Considerações finais}

Os estudos de Schatzki, ao longo de suas pesquisas, avançaram para a definição de sua ontologia e construção de sua teoria. Partindo do pressuposto de que a mente e as atividades estão amarradas ao contexto social, a ontologia plana e a teoria das práticas sociais ganham corpo (SCHATZKI, 2000). Perceber a teoria da prática social de Theodore Schatzki como um caminho de pesquisa que pode ser operacionalizado leva à sua utilização para estudos que saem da área da filosofia, área de base do autor, para outras áreas, como os estudos organizacionais.

Estudos empíricos que têm por base a teoria das práticas sociais beneficiam o campo a partir do momento em que eles evidenciam as organizações como elas de fato acontecem (SCHATZKI, 2006). Ela evidencia a presença de uma estrutura social que gera e também é gerada por meio desta prática e seus praticantes. Então, estudos que buscam compreender como funciona determinada organização podem ser beneficiados pelos caminhos epistemológicos da teoria das práticas sociais no sentido de evidenciar o porquê de certas ações ocorrerem, proporcionando um entendimento real da organização.

O presente artigo teve como objetivo a condução de uma análise sócio histórica do trabalho de Theodore Shatzki no que diz respeito à Teoria da Pratica Social, desenvolvida pelo autor. Dividido em quatro partes, o artigo traz todos os textos do autor relacionados à teoria da prática social, analisados e descritos em ordem cronológica. Para pesquisadores que trabalham ou queiram trabalhar com esta teoria, a análise sócio histórica dos trabalhos de Schatzki aqui presente serve como guia para a exploração dos textos do autor, proporcionando uma visão clara do que buscar em cada texto.

Compreender as origens de uma teoria e da sua base epistemológica, explorando como os elementos foram discutidos ao longo dos anos, acompanhando seu refinamento, traz ao pesquisador uma visão mais embasada. Esta visão é a maior contribuição que o presente artigo traz aos pesquisadores que queiram se valer da teoria da prática social, permitindo uma apropriação da história, base ontológica e elementos desta lente teórica.

Este trabalho traz em sua estrutura também o estudo da ontologia trazida por Schatzki, evidenciando o amadurecimento desta ao longo do tempo, mostrando as três fases ontológicas do autor. Percebe-se que o autor, ao longo do tempo, modifica a forma de caracterizar os elementos que compõem a sua ontologia. O elemento principal da primeira caracterização de sua posição ontológica é o espaço (SCHATZKI, 1999). Em seguida o autor repensa sua ideia sobre a ontologia espacial e reconhece como principal elemento o contexto (SCHATZKI, 2003). Por fim, ele caracteriza esta ontologia como plana, sendo uma só dimensão, sem níveis que separam elementos formadores das práticas sociais (SCHATZKI, 2016).

Esta análise ajuda o leitor a compreender as origens da ontologia plana, percebendo de onde ela surgiu e como ela foi sendo estudada até ser descrita como plana. Esta compreensão traz ao pesquisador uma visão mais profunda desta ontologia, o que facilita o processo de se apropriar desta base para a condução de estudos no campo.

O presente trabalho, a partir do momento em que evidencia as contribuições de ordem ontológica e epistemológica de Theodore Schatzki para os estudos organizacionais, reforça as justificativas teóricas para estudos que são conduzidos a partir destas bases (ontológica e epistemológica). Isso posto, pode-se considerar a teoria da prática social como uma lente teórica que traz ricas possibilidades de pesquisa em estudo organizacionais.

Em resumo, Schatzki, com sua teoria da prática social, traz como principais contribuições aos estudos organizacionais: 1. O rompimento com a tradição positivista; 2. Rompimento com visões reificantes /classificatórias do indivíduo na medida que toma a prática, conceito holístico, como unidade de analise; 3. Rompimento com teorias abstratas que segmentam a organização, percebendo o nexo de dizeres e fazeres nas organizações e; 4. Maior difusão de métodos de pesquisa, como autoetnografia e netnografia. 
Como sugestões de pesquisa na área, Schatzki $(2012,2016)$ deixa evidente que há uma necessidade de estudos empíricos que tenham como base a ontologia plana e sigam o caminho epistemológico da teoria da prática social. O autor aponta a necessidade destes estudos para fortalecer a teoria da prática social como caminho de pesquisa em organizações. Ele destaca o fato de que a ontologia plana proporciona um repensar na forma de fazer pesquisa em organizações, repensando fenômenos, atores e comportamentos organizacionais (SCHATZKI, 2016).

Posto isso, pesquisas empíricas que trilhem o caminho da teoria da prática social em organizações representam uma sugestão que pode trazer novos conceitos, novos dados e novos pensares sobre fenômenos já estudados.

\section{Referências}

BISPO, Marcelo. Estudos baseados em prática: conceitos, história e perspectivas. Revista Interdisciplinar de Gestão Social, v. 2, n. 1, p. 13-33, 2013.

BONDIA, Jorge Larrosa. Notas sobre a experiência e o saber de experiência. Revista Brasileira de Educação, n. 19, p. 20-28, 2002.

BULGACOV, Y.L. M; VIZEU (2011), F. A Positividade da Emoção na Pesquisa. Cadernos EBAPE.

DA SILVEIRA SANTOS, Leonardo Lemos; DA SILVEIRA, Rafael Alcadipani. Por uma epistemologia das práticas organizacionais: a contribuição de Theodore Schatzki. Organizações \& Sociedade, v. 22, n. $72,2015$.

DE FIGUEIREDO, Marina Dantas; CAVEDON, Neusa Rolita. Transmissão do Conhecimento Prático como Intencionalidade Incorporada: Etnografia numa Doceria Artesanal/Practical Knowledge Transmission as Embodied Intentionality: Ethnography in an Artisanal Confectionary Shop. Revista de Administração Contemporânea, v. 19, n. 3, p. 336, 2015.

GHERARDI, Silvia. Introduction: The critical power of thepractice lens'. 2009.

NICOLINI, Davide. Introduction. In: NICOLINI, Davide. Practice Theory, Work, \& Organization: An Introduction. United Kingdom: Oxford University Press, 2013. Chapter I, p. 1-22.

O'KEEFFE, D.; THOMSON, D.; DAINTY, A. Evaluating the design of hospitals within a practice order network. Construction Management and Economics, v. 33, n. 5-6, p. 415-427, 2015.

RECKWITZ, Andreas. Toward a theory of social practices a development in culturalist theorizing. European journal of social theory, v. 5, n. 2, p. 243-263, 2002.

SANDBERG, J.; TSOUKAS, H. Grasping the logic of practice: Theorizing through practical rationality. Academy of Management Review, v. 36, n. 2, p. 338-360, 2011.

SCHATZKI, Theodore R. Social practices: A Wittgensteinian approach to human activity and the social. Cambridge University Press, 1996.

SCHATZKI, T. R. Where the action is (on large social phenomena such as sociotechnical regimes. Sustainable Practices Research Group, Working Paper, v. 1, 2011.

SCHATZKI, Theodore R. A new societist social ontology. Philosophy of the Social Sciences, v. 33, n. 2, p. 174-202, 2003.

SCHATZKI, Theodore R. A primer on practices. In: Practice-based education. SensePublishers, 2012. p. 13-26. 
SCHATZKI, Theodore R. On organizations as they happen. Organization studies, v. 27, n. 12, p. 1863-1873, 2006.

SCHATZKI, Theodore R. Peripheral vision the sites of organizations. Organization studies, v. 26, n. 3, p. 465-484, 2005.

SCHATZKI, Theodore R. Practice mind-ed orders. The practice turn in contemporary theory, v. 11, 2001.

SCHATZKI, Theodore R. Spatial ontology and explanation. Annals of the Association of American Geographers, v. 81, n. 4, p. 650-670, 1991.

SCHATZKI, Theodore R. Subject, Body, Place. Annals of the Association of American Geographers, v. 91, n. 4, p. 698-702, 2001.

SCHATZKI, Theodore R. The time of activity. Continental Philosophy Review, v. 39, n. 2, p. 155-182, 2006.

SCHATZKI, Theodore R. Wittgenstein and the social context of an individual life. History of the Human Sciences, v. 13, n. 1, p. 93-107, 2000.

SCHATZKI, Theodore. Practice theory as flat ontology. Praxistheorie. Ein Forschungsprogramm, Bielefeld: Transcript, 2016.

SCHREIBER, Trine. Conceptualizing students' written assignments in the context of information literacy and Schatzki's practice theory. Journal of documentation, v. 70, n. 3, p. 346-363, 2014. 